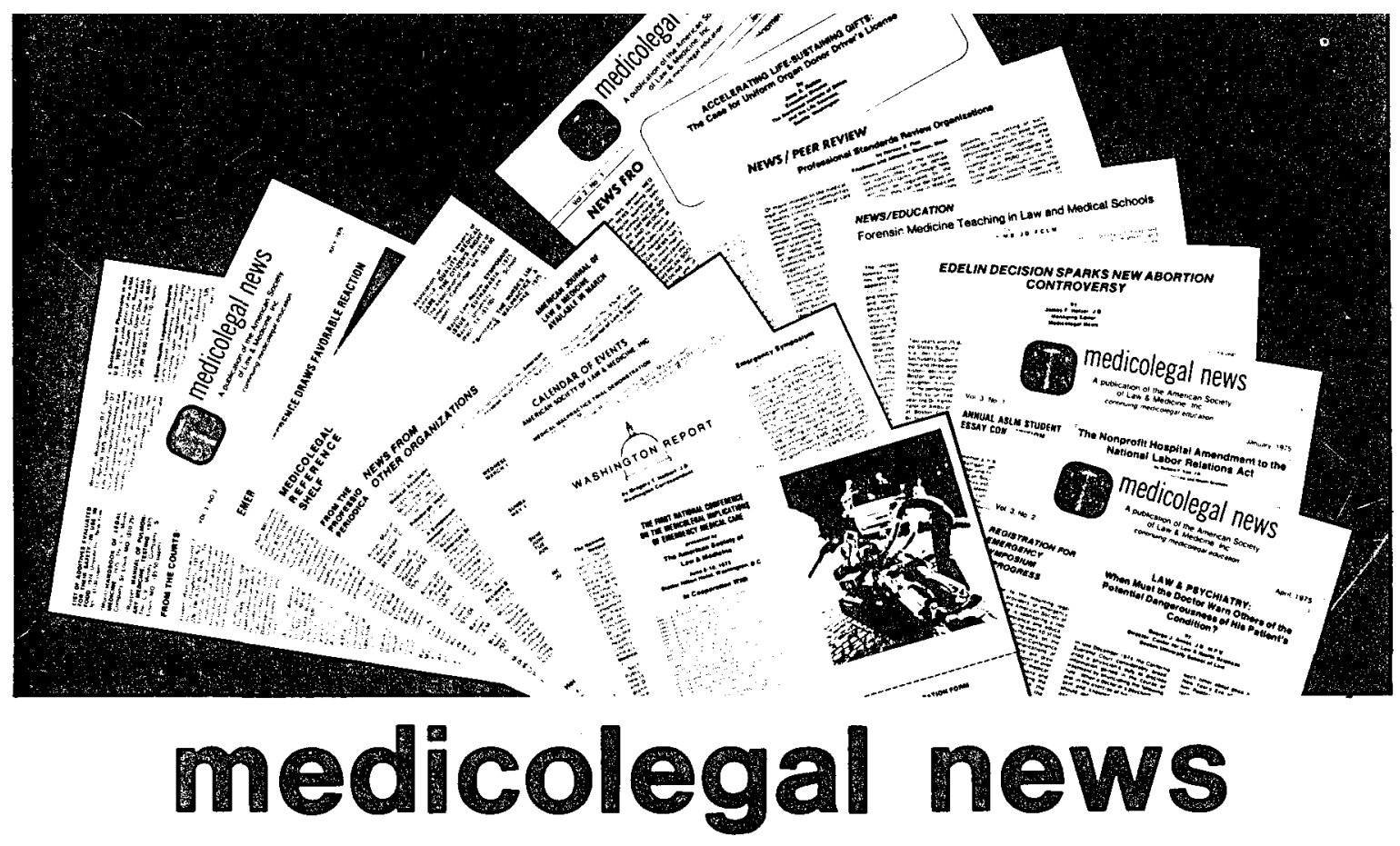

\title{
WHAT'S IN IT FOR YOU?
}

- selected articles on timely medicolegal issues

- feature stories by noted experts in law and medicine

- case citations and summaries of important legal decisions

- up to date listing of current books of medicolegal interest

- current reports on medicolegal affairs from our Washington bureau

- news of seminars and programs from the ASLM

- listing of medicolegal meetings across the nation

- booklets, pamphlets and other medicolegal literature available on request.

\section{... and much more!}

$\square$ Please enter my subscription for the quarterly publication Medicolegal News. Enclosed is $\$ 10.00 *$ for a one year subscription.

I wish to become a member of the AMERICAN SOCIETY OF LAW \& MEDICINE covering initiation fee and free subscription to Medicolegal News and the American Journal of Law \& Medicine. Enclosed is \$25.00.**

Name

Address

City State Zip

Occupation

${ }^{*}$ Canadian and Mexican Subscribers, \$12.50/year.

** See full AJLM ad on the next page.
Mail to: American Society of Law \& Medicine 454 Brookline Avenue Boston, Massachusetts 02215 


\section{The \\ AMERICAN SOCIETY OF LAW \& MEDICINE is many things to many people.}

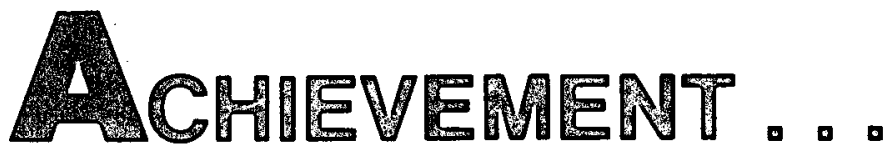

of excellence in the promotion of continuing medicolegal education by providing uniquely conceived programs and in-depth information in the areas where law and medicine interface.

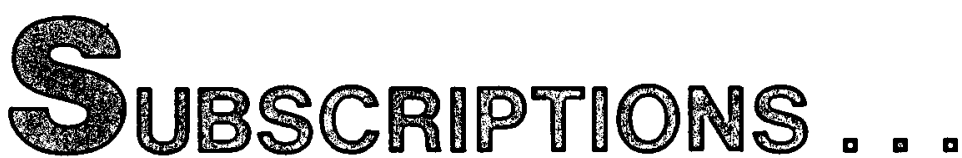

free to the American Journal of Law \& Medicine, Medicolegal News providing articles, reviews, recent cases and other vital information relevant to law and medicine.

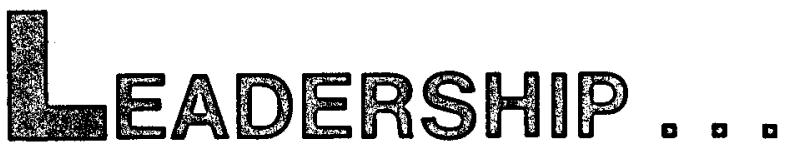

nationally recognized in the field of medicolegal education, with programs and special projects often co-sponsored by the country's leading medical and legal organizations, and accredited for continuing education by such organizations as the American Medical Association and the American Academy of Family Practice.

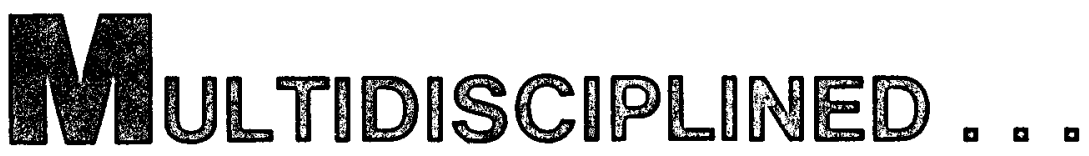

a unique approach providing medicolegal information to physicians, attorneys, health care professionals, jurists, educators and insurance personnel on a multidisciplined basis, with members entitled to reduced registration and admission fees to all ASLM programs and symposia.

\section{MEMBERSHIP APPLICATION}

I wish to become a member of the AMERICAN SOCIETY OF LAW \& MEDICINE

Area of primary professional interest is (check one)

\section{$\square$ Medicine \\ $\square$ Law \\ $\square$ Insurance \\ $\square$ Judiciary or Administrative \\ $\square$ Education}

Attached is my check to the order of AMERICAN SOCIETY OF LAW \& MEDICINE, INC. for $\$ 25.00$ (student membership $\$ 12.50$ ) covering initiation fee and free subscription to the American Journal of Law \& Medicine and Medicolegal News.

\section{Mail to: AMERICAN SOCIETY OF LAW \& MEDICINE 454 Brookline Avenue \\ Boston, Massachusetts 02215}

Name (please print)

Office Address

Home Address

Telephones:

Office

Home 


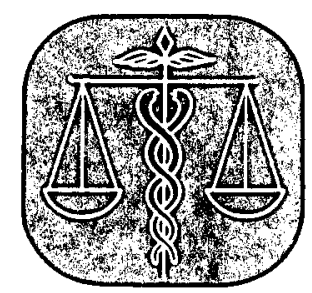

\section{THE AMERICAN JOURNAL OF LAW \& MEDICINE}

The American Journal of Law \& Medicine is a publication of the American Society of Law \& Medicine and is designed to provide its readers with a selection of high quality articles on subjects where law and medicine interrelate. The Journal is published semi-annually and is available only through subscription or membership with the American Society of Law \& Medicine.

A subscription form is provided for your convenience below. Subscriptions or requests for information may be addressed to:

The American Journal of Law \& Medicine

454 Brookline Avenue

Boston, Massachusetts 02215

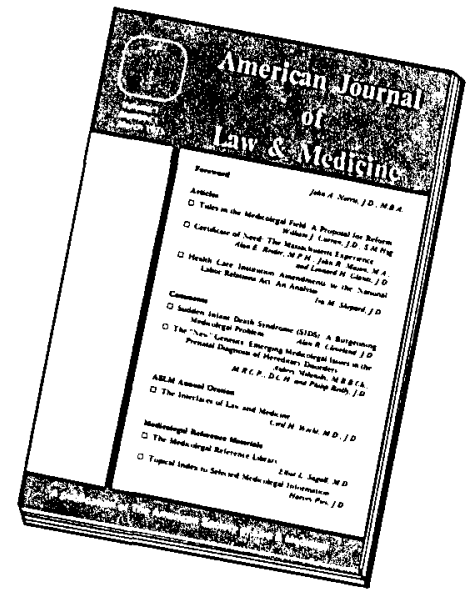

Please enter the name listed below on your list of subscribers for the American Journal of Law \& Medicine.

$\square$ Enclosed is my check for $\mathbf{\$ 7 . 5 0}$ (one calendar year) $\square$ Please bill me

I wish to apply for membership for myself in the American Society of Law \& Medicine, Inc. and a free subscription to the American Journal of Law \& Medicine and Medicolegal News. Enclosed is my check for $\$ 25.00$.

$\square$ Please bill me $\square$ Please send me more information

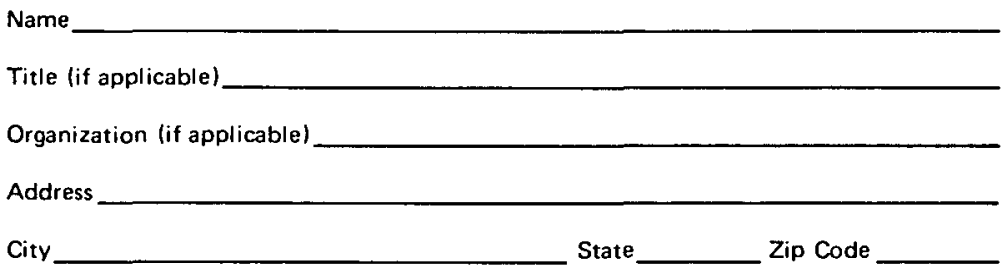




\section{No book too tall \\ Our coldtype does all!}

\section{SERVICE A MUST ?}

\section{WE ARE A}

FULL SERVICE COMPANY

- LAYOUT and DESIGN

- PHOTO TYPESETTING

- ART DEPARTMENT

- CAMERA

- PLATEMAKING

- OFFSET and LETTERPRESS

- FOLDING. TRIMMING. STITCHING

- MAILING

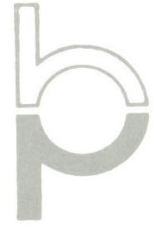

Write or phone 617 791-3661

\section{the heffernan press inc.}




\section{AIMS OF THE JOURNAL}

The American Journal of Law Medicine is published in the interest of members of the American Society of Law \& Medicine, and of those in the legal, insurance and health care professions who seek to further interdisciplinary discussion and knowledge in the areas where law, medicine, government, and insurance interrelate. Publication of any article or advertisement should not be deemed an endorsement of the opinions expressed or products advertised.

\section{REPRINTS AND/OR PERMISSION TO REPRODUCE}

Reprints and/or permission to reproduce material herein should be requested by writing to the Editor-in-Chief, American Journal of Law E Medicme, Editorial Offices, 454 Brookline Avenue, Boston, Massachusetts 02215.

\section{SUBMISSION ()F ARTICI.FS}

The Fditors encourage the submission of manuscripts which pertain to legal and insurance medicine and health law for publication in the Journal. Submission of book reviews, abstracts of recent cases of interest and importance. proceedings of symposia, and digests of important articles in the relevant literature also is welcomed. All materials should be sent in triplicate to the Editor-in-Chief, American Joumal of Laue or Medicime, Editorial Offices, 4.54 Brookline Arenue, Boston. Massachusetts ()2215.

\section{SIYLF ()F MANLSC:RIPI}

General Form: Manuscripts should be typewriten on one side of the paper only. with double spacing and liberal margins. Manuscripts should be submitted in triplicate, i.e., an original and two carbon or Xerox copies. The title of the paper and the author's name and address should be viven on a covering sheet.

Abstract: A short abstract (nomally not exceeding 200 words) succinctly summarizing the content of the manuscript should accompany the manuscript on a separate sheet.

References: Footnotes to sources should appear in the text, numbered consecutively, and placed at the bottom of each page in numerical sequence or on separate pages at the end of the text. Footnotes should include the author's name. initials, title of article in the original language, name of publication with volume. page and year. All footnotes containing references to legal sources should conform to the Uniform System of Citation.

Illustrations: Illustrations and tables accompanying manuscripts should be numbered, provided with suitable legends, and marked lightly on the back with the author's name. Authors should indicate on the manuscript the appropriate positions of tables and text figures. Special arrangements must be made with the Editor-in-Chief for color plates, elaborate tables, half-tone illustrations or extra illustrations, drawings, and photographs.

Publication Language: English.

\section{PROOFS AND AUTHOR REPRINTS}

Because of time pressures, galley proofs of articles accepted for publication will not be made available to authors. Fifty reprints of each article will be distributed to the author or divided among the authors if there are more than one. 